\title{
Immature Lymphocyte
}

National Cancer Institute

\section{Source}

National Cancer Institute. Immature Lymphocyte. NCI Thesaurus. Code C13118.

A cell that develops from hematopoietic stem cells. An immature lymphocyte represents

of one of five stages of lymphocyte maturation. It is estimated $90 \%$ of immature

lymphocytes die in the thymus and bone marrow. 